\title{
A transposição didática na educação física escolar: o caminho formativo dos professores em formação inicial
}

\author{
Luis Eugênio Martiny \\ Pierre Normando Gomes-da-Silva
}

\section{Resumo}

A fim de compreender as manipulações por que passam os saberes até se tornarem ensináveis, o objetivo foi identificar a prática pedagógica dos Professores em Formação Inicial (PFI) quando ministram aulas durante o estágio supervisionado. Participaram da investigação três PFI do curso de Educação Física da Universidade Federal da Paraíba (UFPB). As técnicas de coleta foram: observação participante, grupo focal e documentos escritos. A pesquisa teve a duração de três meses e foi realizada em uma escola pública do município de João Pessoa, no Estado da Paraíba, no primeiro semestre de 2011. Nesse período, foram coletados dados em 24 aulas. Utilizou-se a técnica de análise de conteúdo do tipo categorial por temática. Na análise dos dados, identificou-se um caminho formativo, que auxilia os PFI na sua prática pedagógica, composto de três planos (macro, intermediário e microestruturante), com diferentes esferas e momentos. Esse caminho formativo configurou-se como base da prática pedagógica dos PFI, o que nos sinalizou uma prática com alta tendência reflexiva, constituída por uma intervenção repleta de saberes docentes. Acusa-se, portanto, que a transposição didática é mediada por uma atmosfera que gira ao seu redor.

Palavras-chave: formação inicial; base de conhecimento; transposição didática. 


\section{Abstract \\ Didactic transposition in school physical education: the formative path of teachers in initial education}

In order to comprehend the manipulations through which teaching knowledge passes until it becomes teachable, the aim of this study was to identify the pedagogical practice of Professores em Formação Inicial (PFI - Teachers in Initial Training), while teaching lessons during their supervised internship. Three participants of the PFI, taking the physical education course at the Universidade Federal da Paraíba (UFPB - Federal University of Paraíba), took part in the investigation. The techniques of data collection were based on participant observation, focus group and written documents. The study lasted three months and was held in a public school in the city of João Pessoa-PB, in the first half of 2011. In this period, data were collected in 24 classes. The technique of theme/ category-based content analysis was used. In the data analysis, a formative pathway that helps the PFI in their teaching practice was identified. It was composed of three plans (macro, intermediate and micro), each of them formed by different spheres and moments. This pathway was set as the foundation for the pedagogical practice of PFI. It has pointed out a practice with a highly reflexive tendency, constituted by an intervention full of teaching knowledge. This indicates a didactic transposition mediated by an atmosphere that revolves around it.

Keywords: initial education; basis of knowledge; didactic transposition.

\section{Introdução}

Este artigo fez parte de um projeto de pesquisa mais amplo que teve por objetivo geral analisar como os professores em formação inicial (PFI), alunos do sexto período de Educação Física (EF) da Universidade Federal da Paraíba (UFPB), realizam a transposição didática (TD) dos saberes a ensinar durante o estágio supervisionado (Martiny, 2012). Apresentaremos um recorte daquele estudo, cuja principal finalidade foi identificar de que maneira é realizada a prática pedagógica dos PFI durante o estágio supervisionado. Entendemos que a identificação dessa prática pode nos sinalizar alguns novos elementos de análise para a aplicação da TD.

Dessa forma, verificamos que no âmbito do ensino a complexa estrutura da sociedade atual tem feito com que não somente as práticas pedagógicas dos professores sejam revistas, mas também os seus processos de formação (Ilha; Krug, 2008). A necessidade de mudanças e ajustes nas intervenções práticas e, por conseguinte, nos procedimentos formativos tem tornado o processo de ensinar e aprender ainda mais conflituoso e contraditório. 
No campo de atuação da EF, mais especificamente, a complexidade da docência na área tem gerado significativas discussões acerca da configuração da formação superior. Um dos enfrentamentos que ocorrem diz respeito à perspectiva de estabelecer quais saberes, dentro de um universo expressivo de conhecimentos, habilidades e competências, necessitam ser abordados nos diferentes contextos de formação dos professores.

Quando marcamos essa discussão no âmbito da formação inicial de professores, indicamos que os docentes que se encontram nesse momento de sua trajetória profissional necessitariam apreender (no sentido de constatar, demonstrar, compreender e explicar) um conjunto de saberes, ou a grande maioria deles, a fim de conseguir minimamente se colocar em interação diante de todo o sistema educativo. A apreensão, a transformação e a construção/manipulação desse rol de conhecimentos, habilidades e competências podem até mesmo ir se materializando ao longo da vida acadêmica e profissional desses docentes.

Entretanto, a manifestação dessa pluralidade de saberes, dentro do contexto de formação docente, leva-nos a refletir sobre a relação entre o campo da formação inicial e o campo de intervenção profissional dos professores, possibilitando a problematização de como se dá a transferibilidade de saberes do primeiro para o segundo campo. Para Hernández (2004), essa condição é um dos requisitos que pode garantir a qualidade na educação (pelo âmbito da ação do professor).

Toda essa relação faz com que se torne relevante investigar a disposição dos saberes docentes (SD) no contexto da formação inicial e sua manifestação na prática educativa dos professores em sala de aula. Uma prática que, segundo Perrenoud (1993), é permeada por três faces: a) a face da rotina e improvisação regulada; b) a face do tratamento das diferenças; e c) a face da transposição didática (TD).

Quando se faz referência a esta última, amplia-se a utilização dos SD, em sua transposição para o interior da intervenção prática, para o núcleo do contexto escolar, para dentro da sala de aula. Segundo Leite (2007), por exemplo, pode ser considerada virtualmente unânime a ideia de que existe a necessidade de algum tipo de adaptação do saber quando se trata de ensiná-lo na escola. Chevallard (1998), por sua vez, utiliza o conceito de transposição didática para buscar representar todo esse movimento pelo qual passa o saber até se tornar escolarizável.

Para Chevallard (1998, p. 39),

[...] um conteúdo de saber que tenha sido definido como saber a ensinar sofre, a partir de então, um conjunto de transformações adaptativas que irão torná-lo apto a ocupar um lugar entre os objetos de ensino. O trabalho que faz de um objeto de saber a ensinar objeto de ensino é chamado de transposição didática.

Quando se aprofundam as análises sobre esse movimento do saber, a transposição didática inevitavelmente recai sobre a ação pedagógica dos professores, de modo que se pode identificar dois grupos de saberes 
docentes: a) os saberes para ensinar e b) os saberes a serem ensinados. Esses grupos são adaptados das distintas tipologias dos SD, apresentados por Tardif (2008), que estão presentes na formação inicial de professores.

O primeiro deles, que os professores trazem para o interior da sala de aula, auxilia-os na realização do seu ofício docente, ao passo que o segundo termina por ocupar um lugar no currículo (formal ou oculto) dos programas de educação básica nas escolas. Como vimos, ambos os grupos passam a fazer parte dos SD dos professores.

Diante dessa constatação, deparamo-nos com a seguinte questão problematizadora: como os professores em formação inicial (PFI) conseguem redimensionar os saberes (científicos, disciplinares, das ciências da educação, entre outros), adquiridos na formação inicial, e aplicá-los no contexto escolar?

Na busca por um aprofundamento das duas problemáticas levantadas pela questão, formulamos a seguinte questão norteadora: Como ocorre a transposição didática dos saberes a ensinar na prática pedagógica dos PFI no estágio supervisionado em Educação Física da Universidade Federal da Paraíba (UFPB)?

Para conseguirmos nos aproximar dessa questão norteadora, buscamos, neste primeiro momento, identificar como ocorre a prática pedagógica desses PFI quando ministram aulas durante o estágio supervisionado. A identificação dessa prática pode abrir possibilidades de reconhecimento dos elementos que a sustentam, de suas implicações e definições, como também da transferibilidade dos saberes docentes da formação para a intervenção.

\section{Metodologia}

\section{Caracterização da pesquisa}

Esta pesquisa configurou-se com base no conjunto de nossas escolhas concernentes ao objeto investigado, ao contexto da pesquisa, aos sujeitos que seriam envolvidos e à relação entre todos os atores sociais. Da interatividade com o objeto de estudo, depreenderam-se alguns princípios que caracterizaram esta investigação como uma pesquisa social, de abordagem qualitativa (Minayo, 1999), do tipo ação (Thiollent, 2004), desenvolvida por meio de uma metodologia colaborativa (Bezerra, 2007; Gomes-da-Silva, 2009).

\section{Os Professores em Formação Inicial (PFI) - colaboradores da pesquisa}

Os colaboradores da pesquisa foram PFI do curso de licenciatura em EF da Universidade Federal da Paraíba (UFPB). Como critério de participação 
na investigação, desenvolvemos a pesquisa com os professores que: a) estavam matriculados no componente curricular Prática de Ensino em Educação Física no $1^{\circ}$ semestre de 2011; b) realizariam sua intervenção prática em escolas públicas municipais da cidade de João Pessoa, no Estado da Paraíba; e c) desenvolveriam essa intervenção no ensino fundamental I.

Não adotamos como colaboradores da pesquisa os PFI que: a) já haviam atuado em escola como professor antes da realização do estágio supervisionado; b) já tinham adquirido mais de um ano de experiência docente como professor de escola; e c) possuíam outro curso de magistério e/ou licenciatura.

Inicialmente, tínhamos uma listagem única de 37 alunos matriculados no componente curricular, no $1^{\circ}$ período de 2011. Por meio de consulta, disponibilidade, direcionamento e, por fim, sorteio, reunimos três PFI dois do sexo feminino e um do sexo masculino -, que se disponibilizaram a colaborar com a pesquisa. Durante o processo investigativo, acompanhamos as aulas no ambiente escolar e coletamos informações desses três PFI que aqui serão representados pelos nomes fictícios de Luiza, que ministrou aulas no $1^{\circ}$ ano, Madalena, que realizou seu estágio com a turma do $2^{\circ}$ ano, e João, que trabalhou com a turma do $3^{\circ}$ ano todas as turmas pertenciam ao ensino fundamental I.

\section{Técnicas para coleta de dados}

Para identificar a prática pedagógica dos PFI durante o estágio supervisionado, interpretamos que seria mais pertinente lidarmos com construtos em lugar de variáveis, ou seja, que seria mais adequado trabalharmos com compreensão e interpretação de textos do que com induções. Para tanto, teríamos que utilizar técnicas que nos possibilitassem essa forma de leitura dos dados.

Assim, as técnicas que utilizamos para a coleta de dados foram correlacionadas aos procedimentos da metodologia colaborativa (Bezerra, 2007; Gomes-da-Silva, 2009), que, em virtude dos propósitos do estudo e das características da investigação, foram agrupados, em um primeiro nível, em três diferentes categorias de reflexões temáticas: ontológica, epistemológica e metodológica (Gomes-da-Silva, 2009).

No interior de cada uma dessas categorias iniciais, abrigaram-se outras, que estabeleceram um segundo nível de categorização. Este se decompõe, no conjunto das três categorias iniciais, em oito subcategorias temáticas subsequentes. Dessa forma, a estrutura em torno das categorias e subcategorias que correlacionamos para a coleta de dados ficou estabelecida conforme Quadro 1: 


\section{Quadro 1 - Categorias e Subcategorias Temáticas de acordo com a} Metodologia Colaborativa

\begin{tabular}{|l|l|l|}
\multicolumn{1}{|c|}{ Categoria } & \multicolumn{1}{|c|}{ Subcategoria } & \multicolumn{1}{c|}{ Temática } \\
$\begin{array}{l}\text { Reflexões ontológicas } \\
\text { (RO) }\end{array}$ & Memorial descritivo (MD) & $\begin{array}{l}\text { História de vida } \\
\text { temática }\end{array}$ \\
\hline $\begin{array}{l}\text { Reflexões } \\
\text { epistemológicas (RE) }\end{array}$ & Aurrativa de formação (NF) & Trajetória escolar \\
\hline & Aulas-laboratório (AL) & Cultura escolar \\
\hline $\begin{array}{l}\text { Reflexões } \\
\text { metodológicas (RM) }\end{array}$ & Observação participante (OP) & Observação \\
\hline & Grupo focal (GF) & Diálogo aula \\
\hline & Seminários temáticos (ST) & Discussão \\
\hline & Sessões reflexivas (SR) & Análise crítica \\
\hline
\end{tabular}

Fonte: Bezerra (2007) e Gomes-da-Silva (2009).

Com a finalidade de conseguir colher informações acerca do objeto investigado e dos propósitos da pesquisa, aproximamos as categorias e subcategorias, que estruturam a metodologia colaborativa, das técnicas que poderiam ser utilizadas na coleta. Primeiramente, reagrupamos as subcategorias de acordo com o que se exige dos PFI, em relação à forma de coleta de dados.

Nesse sentido, reagrupamos as subcategorias em três grupos que acabaram definindo a utilização de três diferentes técnicas mediadoras de coleta de dados: a) observação participante (OP), com descrição de comportamento em diário de campo; b) realização de grupos focais (GFs), com perguntas abertas, que se converteram em temas geradores; e c) documentos escritos (DE), pelos PFI, mais especificamente o memorial descritivo, a narrativa de formação e as sessões reflexivas.

\section{Procedimentos metodológicos para coleta de dados}

A pesquisa teve a duração de aproximadamente três meses e foi realizada em uma escola pública da cidade de João Pessoa (PB) no primeiro semestre do ano de 2011. Esse tempo de execução da pesquisa relacionou-se às exigências mínimas de carga horária do componente curricular Prática de Ensino em Educação Física. O componente é cursado no sexto período da graduação em Educação Física da UFPB e tem uma carga horária mínima de 150 horas. Desse tempo total, os alunos matriculados (PFI) necessitam realizar um período não inferior a 100 horas de vivência docente no estágio.

A metodologia de coleta de dados foi estruturada em duas dimensões, que se definiram como macro e microestruturantes, percorrendo toda a ação investigativa. A dimensão macroestrutural foi composta de sete fases e teve um caráter longitudinal ao passo que a microestrutural aconteceu em cada dia de intervenção no estágio e assumiu características 
transversais. A interação entre ambas permitiu a integração entre a formação do professor pesquisador e a análise da TD nas aulas de Educação Física do estágio.

Na dimensão longitudinal, a primeira fase da coleta de dados caracterizou-se por encontros preparatórios/formativos (seminários temáticos) para a realização do estágio. Essa fase foi realizada em dois momentos que aconteceram em sala de aula do departamento de Educação Física da UFPB. No primeiro encontro, houve orientações sobre a elaboração/estruturação dos planos de ensino e de aula direcionados à proposta pedagógica mais votada em sala e adotada pelos grupos de PFI. Essas orientações basearam-se na proposta pedagógica de Corpo Inteiro, de João Batista Freire (1989) e Freire e Scaglia (2009). Ademais, alguns procedimentos didáticos foram tematizados, de acordo com as prioridades de formação didática em EF, de Onofre (1995).

No segundo momento da $1^{\mathrm{a}}$ fase, foram realizadas orientações para a elaboração dos textos das sessões reflexivas (SR). Essas orientações seguiram os quatro tópicos descritos por Magalhães (apud Bezerra, 2007), que norteiam a escrita à reflexão crítica sobre a prática. Esses tópicos foram: a) descrição, que detalha a ação realizada pelos professores; b) informação, que evidencia os embasamentos teóricos que sustentam a ação; c) confronto, que questiona os resultados alcançados pela ação; d) reconstrução, que reflete sobre a possibilidade de um agir/ intervir educativo de outra maneira.

A segunda fase consistiu no reconhecimento do campo do estágio pelos PFI, na ida dos grupos à escola, para tomar consciência do ambiente educacional em que iriam realizar o estágio. Esse contato inicial foi o momento de os PFI visualizarem os espaços da escola - inclusive os destinados às práticas corporais -, de procurarem compreender a dinâmica do contexto educativo e de estabelecerem o primeiro contato com a turma com a qual iriam estagiar. Em decorrência desse primeiro contato, os PFI ainda ministraram uma aula de avaliação acerca da proposta pedagógica escolhida.

A terceira fase marcou um momento de pausa para a reflexão, tempo/ espaço que os PFI destinaram a pensar sobre o que viram e vivenciaram na escola e na sua turma de estágio. Daí surgiu o primeiro texto reflexivo sobre a vivência docente até aquele momento. A quarta fase diferenciou-se por constituir-se pelas aulas-laboratório propriamente ditas. Cada PFI ministrou, nessa fase, um conjunto de três aulas-laboratório, que foram realizadas em proximidade ao tempo de coleta de dados.

Após a sua realização, houve novamente um momento de pausa para a reflexão, que consistiu na quinta fase do processo metodológico: momento de nova elaboração de texto reflexivo, porém agora sobre as aulas ministradas e a continuidade do estágio. Serviu como um pequeno ajustamento - no sentido avaliativo-transformador - dos PFI em relação aos seus desempenhos até aquele momento, às suas fragilidades e às dificuldades encontradas em sala, em relação à turma e ao andamento das aulas de EF na escola. Foi um momento realizado para possível 
reorganização e estruturação da unidade programática, dos saberes que seriam abordados e das estratégias de ensino que seriam mantidas ou alteradas para as aulas-laboratório que ainda seriam realizadas.

O sexto momento, novamente, definiu-se como a efetivação das aulas-laboratório já que os PFI ministraram um conjunto de cinco aulaslaboratório. Por fim, ao término das aulas, houve uma nova pausa para a reflexão (sétima fase). Nesse instante, os PFI fizeram não somente uma avaliação transformadora acerca do estágio, mas também uma autoavaliação formativa em relação aos seus saberes docentes, à sua identidade de professor, aos procedimentos utilizados nas aulas e aos conteúdos ministrados.

No decorrer do período do estágio, cada um dos PFI ministrou um total de 21 aulas de EF no ambiente escolar, que corresponderam ao período de um bimestre letivo e foram realizadas sistematicamente nas segundas, quartas e sextas-feiras, no turno da tarde. Todavia, conforme o recorte efetuado e as limitações apontadas, conseguimos observar e registrar um total de oito aulas de cada um dos PFI.

Desse conjunto de aulas, os PFI conseguiram desenvolver, no mínimo, duas unidades programáticas distintas. Cada aula ministrada seguiu o tempo de 40 minutos de duração, conforme os períodos da escola. Todavia, o tempo efetivo de aula, na média de todas as aulas realizadas pelos PFI, ficou em 30 minutos. Foram observadas e registradas 24 aulas para coleta e posterior análise de dados de um total de 63 aulas.

Em todos os dias de intervenção no estágio, os três PFI ministravam, cada um deles, uma aula da sequência progressiva de 13h, $13 \mathrm{~h} 40$ e 14h20, que nos possibilitou o acompanhamento de todas as aulas em todos os dias do estágio. Em conformidade com a realização de cada uma dessas aulas, em cada um dos dias do estágio, materializou-se o segundo procedimento metodológico (transversal), em afinidade ao primeiro (longitudinal), ambos em consonância com as finalidades da pesquisa.

O tempo dos PFI no ambiente do estágio, em cada dia, iniciava-se às $13 \mathrm{~h}$ e terminava às $17 \mathrm{~h}$. No transcorrer dessas quatro horas, cada um ministrava uma aula e observava as aulas de, no mínimo, outros três colegas. Em nosso caso, para a coleta de dados, optamos por fazer uma observação participativa descritiva. Procuramos, durante a observação, ater-nos a descrever a aula e, por conseguinte, as ações instrutivas do PFI que estava sendo observado, conforme elas realmente aconteciam.

Durante a descrição, tentamos manter certo distanciamento de escritas que pudessem apresentar juízos de valor em relação às ações executadas pelos professores. Essa tentativa de imparcialidade na observação e, portanto, na escrita da leitura dos fatos, também permitia certo direcionamento na forma de mediar a discussão no grupo focal (GF). Os GFs, que aconteciam logo após o término do conjunto de aulas, acompanharam o andamento dos dias das aulas no estágio, de modo a perfazer oito encontros, com uma duração de 35 a 40 minutos, em média.

Um GF foi realizado logo após a aula avaliativa (durante a segunda fase da pesquisa) e teve a duração de 15 minutos, aproximadamente. 
O tempo desse GF foi destinado à identificação de problemas até então percebidos pelos PFI (após a visita à escola e o contato com a turma). Em desdobramento a esse GF, constatamos a presença de elementos da transposição didática como problema sinalizado pelos PFI.

A partir de então, procuramos sempre iniciar os GF com um questionamento que os levava a fazer um pequeno relato sobre suas ações nas aulas. Era um primeiro momento para incitá-los a pensar sobre o que fizeram, a refletir sobre a aula ministrada. Após esse tempo de relato reflexivo (avaliativo e transformador), os outros PFI manifestavam suas opiniões em relação à aula observada e aos apontamentos feitos pelo próprio PFI.

Todos os envolvidos no GF, a partir de então, permaneciam em constante diálogo. Esses diálogos se seguiam na busca de ajustes, na apresentação de opiniões contrárias ou convergentes, nas manifestações de inquietações em relação às dificuldades da turma, entre outras aflições. Para finalizar o GF, buscamos sempre estabelecer, nas discussões firmadas, uma possível continuidade com a aula seguinte, no sentido de melhorar o desempenho dos PFI no próximo encontro com a turma.

Como a metodologia se apresentou bastante desafiadora, realizamos a coleta de dados por meio de uma ação contínua que se estabeleceu em três etapas: a) antes do início das aulas do estágio, com a coleta do memorial descritivo e da narrativa de formação; b) durante a realização das aulas do estágio, com a coleta das sessões reflexivas 1 e 2 e das observações participantes (registros dos comportamentos em diário de campo) e com a realização dos grupos focais (gravação de áudio); e c) após o término das aulas do estágio com o registro da sessão reflexiva 3.

Todo esse material construído foi coletado na prática de Luiza, Madalena e João, durante todo o processo metodológico. Para fins de tratamento e análise das informações coletadas, todas as falas realizadas no GF foram transcritas. Após a transcrição, essas falas foram devolvidas a Luiza, Madalena e João, para que autorizassem sua publicação. Cabe ressaltar também que o projeto foi aprovado no comitê de ética da UFPB pelo protocolo $n^{\circ}$ 032/2011.

\section{Tratamento e análise das informações coletadas}

Para análise e tratamento das informações coletadas, foi adotada a proposta de análise de conteúdo de Bardin (2008). As análises seguiram um roteiro didático (adaptado de Souza Jr.; Melo; Santiago, 2010) e foram organizadas em três fases distintas: a) a pré-análise, relacionada à organização dos documentos; b) a exploração do material, direcionada à codificação dos textos/mensagens (recorte, enumeração e classificação); e c) o tratamento dos resultados, a inferência e a interpretação, voltados ao estabelecimento de sentidos e significados às mensagens analisadas. Concomitantemente, também foram estabelecidos os critérios de análise.

Para que as apreciações pudessem acontecer, foi utilizada a técnica de análise de conteúdo do tipo categorial por temática, o que nos 
possibilitou, de certo modo, organizar as mensagens. A partir de então, foram catalogadas em categorias temáticas as informações coletadas por meio dos textos escritos, das falas e das observações registradas em diário de campo. Essas categorias, em um segundo nível de aprofundamento, foram estruturadas em unidades de contexto e de registro.

Para tanto, como primeiro passo, foi construído um mapa estruturante de análise de dados, configurado por grupos de aproximação. O segundo passo efetuado foi a identificação de falas, escritos e observações (FEO). Estes foram caracterizados como as mensagens que apresentaram em seu significado relações com a transposição didática, os saberes docentes dos PFI e a sua atuação.

Por fim, o conjunto de FEO foi interpretado, mapeado e correlacionado entre as categorias temáticas e suas unidades catalogadas. Essa análise possibilitou a identificação da prática pedagógica dos PFI, as sinalizações com a transposição didática e os saberes docentes, assim como o reconhecimento das estratégias de ação e das formas de TD presentes na ação dos PFI. Para conseguir avaliar as falas, escritos e observações, a análise foi realizada com base na teoria dos SD e da formação profissional de Tardif (2008), em interlocução com a teoria da TD de Chevallard (1998).

Conforme o objetivo apresentado anteriormente, neste estudo concentramo-nos na apresentação do mapa estruturante, assim como nos achados da investigação acerca da categoria temática (CT) formação. Mais especificamente, vamos fazer a descrição dos resultados encontrados sobre a categoria do componente curricular.

\section{Resultados}

A unidade de contexto (UC) identificada, sobre as falas, escritos e observações dos PFI, dentro da categoria temática componente curricular, foi a prática pedagógica, que se caracterizou em relação ao processo metodológico colaborativo do estágio supervisionado e incidiu sobre a atuação desses professores.

A proximidade da atuação com a metodologia colaborativa permitiu a identificação da prática pedagógica dos PFI. Para reconhecer as unidades de análise, tivemos que aproximá-las à estrutura dos processos metodológicos da investigação, tendo estes suas dimensões macroestruturantes (em suas fases longitudinais) e microestruturantes (em seus níveis transversais). Ao fazermos essa aproximação, conseguimos identificar, dentro de um contexto mais amplo, o caminho formativo.

O caminho formativo identificado, então, manifestou-se na atuação dos PFI e seguiu o andamento do componente curricular que assumiu princípios da metodologia colaborativa de Gomes-da-Silva (2009). Esses princípios buscavam fazer com que os professores refletissem sobre suas ações, compreendessem os elementos que condicionam a sua prática, entendendo-a como um momento de construção de conhecimento.

$\mathrm{Na}$ identificação desse caminho formativo, reconhecemos três planos de atuação que compuseram três diferentes esferas formativas. 
Essa configuração deu-se em diferentes tempos e espaços, porém houve um percurso integrativo entre os planos. Isso significa que um plano de atuação, com suas respectivas esferas, auxiliou na composição do outro e/ou acabou trazendo seus elementos para a sua própria configuração.

O primeiro plano, com uma esfera macroestrutural/funcional, desenvolveu-se durante todo o semestre letivo, possibilitando a abertura de diálogos entre o que acontecia nas situações concretas de sala de aula e os discursos teórico-práticos abordados no componente curricular. O plano permitiu, portanto, discussões acerca dos saberes docentes da formação, tais como: propostas teórico-metodológicas da Educação Física, estratégias de ensino-aprendizagem e elementos didáticos a serem desenvolvidos durante as aulas com o saber-fazer vivenciado pelos PFI no campo de intervenção.

A dinâmica desse plano incidiu sobre três momentos que se complementaram e se revezaram: o primeiro caracterizou-se como de formação, consistindo em encontros para discussão de saberes vinculados a auxiliar a prática dos PFI ou minimizar as dificuldades enfrentadas em sala de aula; o segundo definiu-se como de ação, período que atendia às intervenções propriamente ditas dos PFI na escola; e, por fim, o momento de reflexão, tempo-espaço de pausa para os PFI refletirem sobre a prática, mais especificamente sobre as aulas que realizaram até aquele instante, confrontando todos os aportes teórico-práticos utilizados.

Ao retomar o ritmo de ação, os PFI passavam por um novo momento de formação, por meio de seminários temáticos. Essa formação complementar abria caminhos para uma nova ação, um novo período de atuação na escola, e isso desencadeava uma nova reflexão. É importante esclarecer que o conceito de novo, aqui, não se remete, exclusivamente, à ideia de total mudança do PFI em relação a cada um dos momentos. A novidade aqui pode se manifestar simplesmente na dimensão de uma tomada de consciência sobre todo o processo de intervenção. A conscientização permite gerar, inclusive, uma melhor percepção do PFI sobre sua atuação. Esse plano, com seus distintos momentos, pode ser percebido nos escritos de Luiza, João e Madalena, que apresentaremos a seguir.

Na primeira produção textual de Luiza, por exemplo, inicialmente ela expõe um momento da formação. Relata o que aconteceu em um dia no cronograma do componente curricular que foi destinado à tematização das propostas pedagógicas presentes na Educação Física. Ao compararmos esta com a segunda produção textual, vamos perceber a passagem do momento formativo para o momento de ação. Essa transição configura-se quando Luiza apresenta os motivos que a levaram a adotar uma das propostas tematizadas e aplicá-la em sala de aula.

No dia 16.03.2011 o professor [do componente curricular] fez uma revisão geral das propostas pedagógicas sistematizadas apresentando orientação para elaboração do plano de ensino. Ele nos falou sobre as diversas abordagens da educação física, sendo elas: Educação Física Desenvolvimentista onde os autores são Gallhaue e Ozmun dos Estados Unidos cuja meta é estilo de vida ativo e seu objetivo as 
habilidades motoras; Educação Física Psicocinética onde o autor é Le Bouch da França e sua meta é imagem corporal e seu objetivo praxias psicomotoras; Educação Física de Corpo inteiro, seu autor João Batista Freire, sua meta autonomia e solidariedade e seu objetivo é o corpo inteiro; e Educação Física critíco-superadora, onde seus autores são Soares et al, cuja meta está relacionada à superação do capitalismo e seu objetivo é a cultura corporal (Luiza - sessão reflexiva - descrição).

Acredito que ao longo dos meus [anos de vida], tive muito a observar, analisar e saber criticar corretamente o que considero necessário e essencial para acrescentar no cotidiano dos alunos que pretendo ministrar as aulas. A proposta de João Batista Freire vem a calhar nesta minha nova jornada, pois é uma proposta de corpo inteiro, ou seja, proporciona as melhores coisas da vida para os melhores momentos da vida escolar: ludicidade, interação, afeição, trabalho em equipe, além das diversas habilidades a serem desenvolvidas e aperfeiçoadas (Luiza, sessão reflexiva - narrativa de formação).

Quando analisamos o escrito de João, a seguir, percebemos que o PFI parte da reflexão de uma situação vivenciada que desencadeia uma ação. Essa ação provoca uma reflexão que termina em um momento de formação. Esse novo tempo-espaço vai possibilitar, na prática de João, a adoção de uma nova estratégia de ação.

Com o conhecimento da turma e suas carências, comecei a ministrar minhas primeiras aulas para a turma, e foram bem difíceis, pois alguns alunos queriam me testar e comandar a aula, mas, percebendo isso, comecei a utilizar dos próprios alunos para identificação daqueles que atrapalhavam a aula, como também utilizei, por algumas aulas, a aluna problema Carolina como minha ajudante, assim ela tinha uma função e ganhava uma importância na aula, tornando-a útil e não perturbadora da aula. Contudo, por mais que aplicasse algumas mudanças na aula, e métodos de condução da aula, esses alunos continuavam a querer se destacar e atrapalhar minha aula. Então, graças ao Professor [do componente curricular], através da explicação dos combinados foi que criei regrinhas para aula para que os alunos seguissem e houvesse um melhor comportamento. Passei então a falar para eles, oralmente, quais eram as regras de nossas aulas. O resultado foi bom, mas ainda não havia sanado alguns problemas. Então o professor [do componente curricular] falou para que criássemos joguinhos dos combinados para despertar o interesse de aplicação das regras dos combinados pelos alunos (João - sessão reflexiva - autoavaliação).

Por fim, já no escrito de Madalena, podemos perceber o momento da pausa para a reflexão, tempo destinado a pensar sobre a atuação no estágio. Esse período traz implicações inclusive na forma de se perceber como professora de uma turma de alunos e/ou de propor encaminhamentos para as aulas futuras.

Acredito que estou muito na defensiva e trabalhando muito como uma mãe super protetora e estou tirando deles a oportunidade de me surpreender e mostrar que eles são capazes sim de se tornarem pessoas civilizadas e educadas o suficiente pra brincarem de maneira mais solta, de modo que haja mais corpo a corpo. Vou apostar um pouco mais em brincadeiras que antes enxergava como potencialmente perigosas, tais como brincadeiras com bola e também tentarei acrescentar algo mais interdisciplinar, afinal de contas eles estão em fase de alfabetização e 
formação de caráter, então tentarei deixá-los ser um pouco mais criança e menos alunos, acredito que os jogos com regras deixarão as aulas mais interessantes (Madalena - $2^{\mathrm{a}}$ sessão reflexiva).

Nos quatro escritos apresentados podemos perceber a presença da transição entre os momentos dentro do plano macro, marcada por interações de idas e vindas entre eles. Há um momento de formação que gera uma ação, seja ela de escolha e/ou intervenção que, por conseguinte, provoca uma reflexão. A reflexão, então, vai deixar o PFI em condição de maior consciência para dialogar em um momento de formação e para enfrentar as novas ações.

O segundo plano de atuação, que se manifesta em uma esfera intermediária, aconteceu entre uma aula e outra ou entre uma unidade programática e outra, caracterizando-se como uma interface ativa (no sentido transformador) entre os saberes docentes da formação e os saberes que provinham da experiência em sala de aula. Assim como o plano anterior, este também se desenvolveu em três momentos que se imbricaram.

O primeiro deles relevou o momento da ação/observação, quando os PFI ministravam as suas aulas ou observavam as dos colegas. Após esse período vinha o tempo da reflexão, que se iniciava na observação das aulas ministradas pelos colegas e continuava dentro do GF. Durante a realização do GF, os PFI traziam suas impressões e anotações. Feito isso, engendrava-se, então, um terceiro momento, que se definia como nova ação/observação e se materializava na próxima aula a ser realizada/ observada. Uma descrição desse plano pode ser percebida na escrita de João, que apresentamos a seguir, quando este reconhece a importância desses momentos para a melhora como docente.

Também devo muito a melhora do meu desempenho nas minhas aulas, não só ao meu professor [do componente curricular], ao meu supervisor e ao monitor da disciplina, mas também aos meus companheiros(as) de grupo: Luiza, Madalena e Fernando ${ }^{1}$, pois com eles aprendi bastante e, em vários momentos, foi neles que busquei inspiração e medidas para solucionar alguns problemas que eu tinha. Logo no início, eu tinha dificuldade em chamar a atenção de todos, apesar de ter um tom de voz forte. Mas observando as aulas de Madalena aprendi a usar mais as mãos, através de gestos e palmas. Foi de grande utilidade. Nas aulas de Luiza, observei que sempre no $1^{\circ}$ momento ela explicava a atividade e demonstrava utilizando algum aluno, facilitando assim a compreensão dos mesmos, e isso me chamou a atenção e também levei para praticar nas minhas aulas. Com Fernando aprendi a trabalhar e falar mais forte e firme para que os alunos tivessem mais respeito e prestassem mais atenção nas explicações. Enfim, durante todo esse período eu cresci muito como professor, pois foi minha primeira experiência na área, mas não tive grandes dificuldades não, pois consegui lidar perfeitamente com a minha turma, a qual era uma das piores do colégio e, ao menos nas minhas aulas, as professoras admiravam o comportamento deles e a colaboração comigo (João - sessão reflexiva - autoavaliação).

1 Fernando é o quarto integrante do grupo, outro PFI, todavia não foi selecionado como sujeito de pesquisa.

João, no seu escrito, deixa evidente que começou a adotar comportamentos dos seus colegas por meio da observação e das discussões 
realizadas no GF. Ao aceitar essa ajuda, ele conseguiu minimizar as dificuldades encontradas durante o estágio, pois quando observava e, posteriormente, discutia no GF, ao voltar a ministrar sua aula já incorporava estratégias usadas pelos outros PFI. Esse procedimento acabou gerando uma nova ação, mais consciente, problematizada e segura.

Todavia, detectamos outro aprofundamento, um intervalo que se apresenta entre a realização da aula, a observação participante e a composição do GF. Esse intervalo nos abriu a condição de identificar um terceiro plano de atuação que assumiu uma esfera microestrutural/ funcional, desenvolvendo-se durante a realização de cada aula dos PFI.

Esse plano caracterizou-se pela ação/reflexão imediata, ou seja, pelo desenvolvimento das ações do professor durante a aula. Quando agia, ministrava a sua aula, o PFI já refletia. Essa reflexão sobre a ação imediata desencadeava manutenções e/ou mudanças sobre a atividade que estava sendo realizada e/ou sobre a própria ação do professor ou ainda sobre a estrutura da sua aula. Essa situação pode ser vista na fala de João a seguir, quando, dentro do GF, faz uma descrição da aula que acabara de ministrar.

Eu acho que hoje eu improvisei é... uma atividade, porque hoje eu tinha "botado" só no plano de aula isso, aí eu fiz uns ajustes, só que aí eles tinham que ficar em cima da linha que eu ia traçar. E quando eles ficavam num vai e vem, de pular em cima da linha, eu falei: "Vocês vão apagar". E eu quero trabalhar que eles formem [inaudível], que eles fiquem em fila pra justamente saber a direita e esquerda. Aí eu falei: "Se vocês ficarem em cima vai apagar". Aí eu tive que pegar... eu ia pegar um cone, mas aí não tinha no plano de aula, aí eu pensei: "Se eu não colocar o que tá aqui (no plano) vai dar errado". Aí eu peguei... pedi uma sandália deles lá, pra formar, tipo... um campo (João - $3^{\circ}$ grupo focal).

Além da fala de João marcar a dinâmica que acontece dentro de uma aula, também se apresenta uma tensão existente entre o plano de aula elaborado (imaginário) e o plano de aula realizado (real). Nessa tensão, João se deparou com um conflito percebido, porém não previsto, dentro da aula real, que o fez buscar uma improvisação para continuar a atividade. Essa improvisação não foi desprovida de reflexão acerca da escolha do procedimento que ele teria que adotar para manter a realização da tarefa e conseguir atingir o objetivo para aquela aula. Portanto, houve uma ação que gerou uma reflexão e provocou uma nova ação durante a realização da aula, alterando seu andamento.

O Gráfico 1, a seguir, apresenta todo esse caminho formativo com os seus três planos de atuação, seus vários momentos e suas diferentes esferas; representa, ainda, as inter-relações e as ligações que se estabelecem entre os planos, as esferas e os momentos. Essas conexões inclusive podem ser evidenciadas nas próprias falas e nos escritos dos PFI que apresentamos anteriormente.

Uma ação/reflexão realizada dentro da aula desencadeia uma nova ação para a próxima aula ou provoca uma mudança para outra unidade programática, ou, ainda, essa situação vivenciada é levada para dentro de um ambiente de formação. O inverso também acontece. Como 
presenciamos no documento escrito de Luiza (na sua primeira produção textual apresentada anteriormente), quando, com base na tematização das propostas pedagógicas em um momento de formação, passou a adotar e aplicar uma delas em sala de aula.

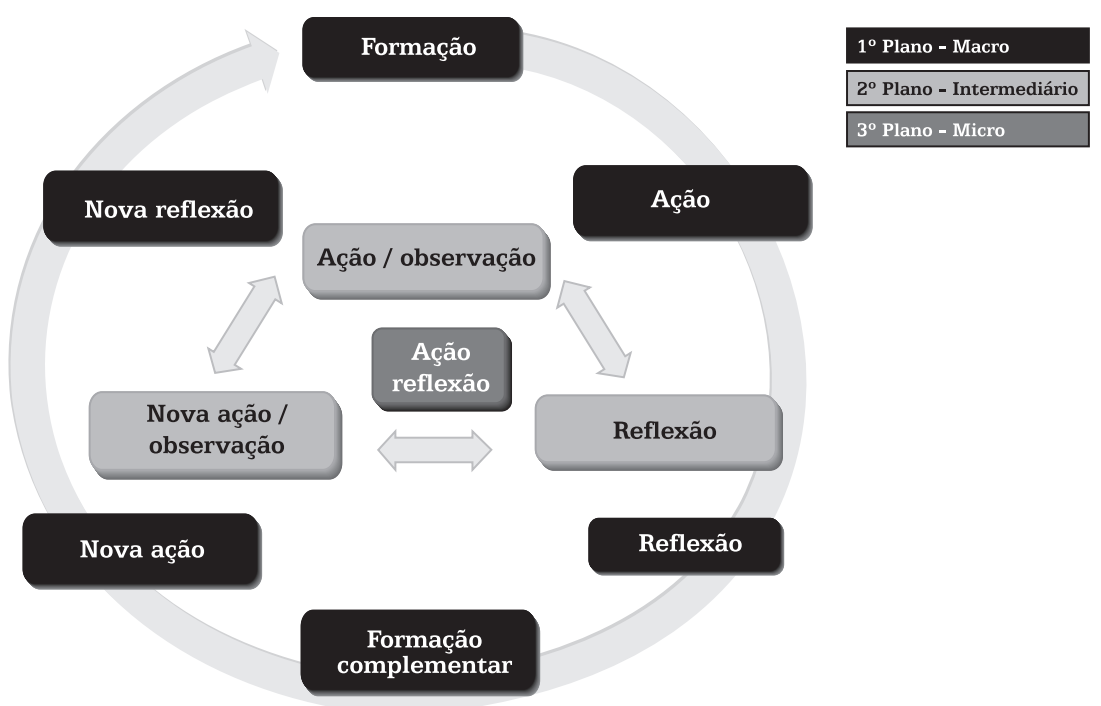

Gráfico 1 - Caminho Formativo dos PFI sobre a Prática Pedagógica com seus Três Planos, Esferas e Momentos

As inter-relações entre os planos, os momentos e as esferas remetem à ideia de certa continuidade e não linearidade sobre o processo formativo dos PFI. As ligações ambivalentes (de sentidos múltiplos) e complementares entre si despertaram compreensões indicativas de espiralidade e transversalidade sobre o agir dos PFI, que, portanto, refletem sobre suas práticas pedagógicas. Tais configurações se manifestam nas ações e nos saberes criados/utilizados/manipulados pelos professores durante as aulas. Essa compreensão, inclusive, pode entrar em oposição a uma suposta configuração acumulativa da formação, que leve a uma possível instrumentalização do agir docente.

O conjunto de todas essas ações/descrições apontadas/identificadas nesse caminho formativo terminou por fazer parte, como base estruturante, da prática pedagógica dos PFI. Uma base com características sólidas, porém com grande mobilidade, não fixa ou estanque, mas sim flexível, que se teceu conjuntamente com o desenvolvimento do componente curricular.

\section{O caminho formativo em discussão}

A identificação do caminho formativo percorrido pelos PFI na realização da sua prática pedagógica possibilitou a configuração de uma 
estrutura que antecede os elementos que a sustentam. A caracterização desse caminho, com o reconhecimento dos seus três planos de atuação, com suas três esferas formativas e com seus elementos constitutivos, sinalizou para uma base estruturante da prática desses docentes.

A diferenciação do caminho formativo como base estruturante da prática remete a aproximações com os estudos de Borges (2001; 2004), Marcon, Graça e Nascimento (2007) e Tardif (2008). Para esses autores, existe um conjunto de saberes que está na base da profissão dos docentes, uma base de conhecimento (knowledge base) que, para Shulmann (1986), se define com um corpo de compreensões, saberes, habilidades, disposições e competências que um professor necessita ter para conseguir atuar efetivamente numa dada situação de ensino. Essa base, portanto, vai ganhando forma e consistência ao longo do processo de intervenção do professor.

O caminho formativo percorrido pelos PFI auxilia-os na construção dessa base de conhecimento com fundamento em suas práticas pedagógicas, visto que ao longo do seu desenvolvimento, conforme apontado nos resultados, os PFI vão adquirindo, mobilizando, criando, fixando e testando não somente estratégias de ensino, abordagens metodológicas, mas também um conjunto de saberes provenientes da formação inicial, além de incorporarem a experiência à profissão de professor.

Esse repertório de saberes, que vai se tecendo ao longo do estágio (no nosso caso em questão) e ao longo da trajetória docente num sentido mais amplo, termina por fazer dessa base de conhecimento o que Almeida e Biajone (2007) denominaram de um reservatório de saberes. Para Gauthier (2006), isso ressignifica o olhar para o professor, que passa a ser visto como um profissional autônomo que delibera, julga e toma decisões.

Então, compreendemos que o caminho formativo acaba assumindo duas especificações como base estruturante. Ao mesmo tempo que absorve, dialoga, cria, confirma e deposita saberes, ela serve também como uma espécie de plataforma que sustenta a prática pedagógica dos PFI, além de auxiliá-los na construção do seu saber ser professor. A resultante desse conjunto de duas funções é a deliberação de que a base é ao mesmo tempo sólida e flexível, o que, a nosso ver, confirma a compreensão de espiralidade e transversalidade sobre o agir dos PFI, que, por sua vez, se apoia nessa base estruturante.

Diante dessa sinalização, teríamos que considerar os achados de Borges (2004) em conjunto com as observações de Garilio (2006). Para esses autores, existem práticas docentes marcadas pela pluralidade do contexto de ação. Se houvesse um contexto que regulasse e refletisse a prática dos docentes, teríamos que problematizar a própria funcionalidade do estágio supervisionado uma vez que a identificação do caminho formativo ocorreu dentro desse ambiente, com sua estrutura e funcionalidade correspondente. 
Nesse sentido, alguns autores, entre os quais Mateus et al (2002) e Moreira e Pereira (2007), nos seus estudos referentes à relevância do estágio para a formação do professor, têm apontado que os PFI consideram essa experiência significativa para as suas vidas profissionais. Constatou-se também que a experiência do estágio configura-se como uma das principais fontes de aquisição de conhecimentos e habilidades para o bom professor.

Contudo, Mateus et al (2002) já apontam para certa exposição negativa que, no estágio, os professores em formação inicial podem sofrer. No entendimento dos autores, o processo de os PFI irem à escola ministrar aulas pode gerar um enfrentamento negativo se não for bem estruturado. Dessa maneira, eles terminam por questionar as formas de realização do estágio no processo de aprender a ensinar.

Marandino (2003), por meio das suas investigações, tem notado uma postura negativa nos PFI em relação ao estágio, principalmente pela justificativa de que a escola brasileira - especialmente a pública - possui tantos problemas que se torna incapaz de proporcionar as vivências que os licenciandos necessitam experimentar em sua formação inicial.

Em complementaridade ao que já foi exposto, Ferreira (2002) faz críticas à estrutura de realização do estágio. Em sua investigação, ela relata que, na maioria das vezes, um único professor (responsável pelo componente) necessita atender/supervisionar 35 PFI. Muitas vezes, os estagiários vão à escola desassistidos, sozinhos, tendo o professor do componente como única referência docente. Isso quando não fazem do estágio somente um observatório da prática dos professores efetivos da escola, o que, para Miranda (2008, p. 15), acaba reduzindo o estágio "a uma atividade de prática instrumental que limita o papel do alunoestagiário (PFI) a mero observador e, consequentemente, empobrece as possibilidades de ação na escola-campo".

Ferreira (2002) vai além, pois entende que essa estrutura tem reforçado a crise de insegurança que normalmente está presente na realidade do estágio e que se manifesta na ação dos PFI. Nessa composição, as situações-problema vivenciadas só desvelam mais ainda esse sentimento de impotência dos PFI perante a realidade e sua intervenção prática. Isso reforça a afirmação de Mateus et al (2002) de que há limitações de impacto da prática de ensino sobre o processo de aprender a ensinar reflexivamente numa perspectiva crítica em razão de os PFI se encontrarem em estágios elementares de seu desenvolvimento docente.

Entendemos que os resultados que encontramos por meio das falas, escritos e observações participantes caminham para um sentido oposto ao evidenciado por esses estudos. Quando Madalena escreve que foi difícil se encontrar como professora, mas que, ao longo do tempo, começou a perceber essa transformação (sessão reflexiva), ou quando João escreve que aprendeu muito observando as aulas dos colegas ( $2^{\mathrm{a}}$ sessão reflexiva), ou ainda quando Luiza escreve que incorporou atitudes e metodologia graças aos momentos de formação (narrativa de formação), isso já denota 
certos avanços em relação ao estágio e à sua forma de concepção e estruturação.

Esses avanços ficam ainda mais evidentes quando João declara que, em todo o tempo do estágio, não se acostumou a ser o mesmo, revia constantemente suas formas de ensino, procedimentos adotados e abordagem metodológica utilizada (sessão reflexiva - autoavaliação). Esse procedimento acabou gerando em João a construção de uma cultura reflexiva permanente sobre a sua ação/intervenção.

Poderíamos ainda assinalar que essa estrutura assumida pelo estágio - conforme identificação do caminho formativo e da metodologia da pesquisa - facilita e marca a transição de aluno para professor. Uma transição que é acompanhada, compartilhada e refletida, principalmente quando os PFI começam a refletir sobre suas ações para facilitar a aprendizagem dos alunos. A reflexão está correlacionada também à cultura escolar e às suas próprias ações.

A transformação do eu-professor que essa estrutura de estágio possibilita é denominada por Feiman-Nemser e Buchmann (1989) de transição para o pensamento pedagógico. Na transição de aluno para professor, os PFI começam a pensar sobre o que fazem na condição de docentes, em termos do que os seus alunos podem e devem aprender.

Nesse sentido, nos aproximamos de Perrenoud (2002) quando este afirma que a formação de bons principiantes está atrelada, acima de tudo, à formação de pessoas capazes de evoluir, de aprender de acordo com a experiência, refletindo sobre o que gostariam de fazer, sobre o que realmente fizeram e sobre os resultados alcançados. A caracterização do caminho formativo e os avanços alcançados em razão deste nos direcionam para essa compreensão.

Tudo isso acontece em virtude de os procedimentos utilizados no componente curricular criarem um ambiente clínico/laboratorial para a prática dos PFI. Essa constatação se verifica no momento em que a estrutura do estágio prepara o PFI para refletir sobre ele, com ele e com base nele, além de permitir ao PFI criar projeções espelhadas sobre sua forma de atuação, assim como dialogar sobre as ações dos seus colegas, incorporando-as, e auxiliá-los, de modo que realiza análises teóricopráticas baseando-se nas experiências vivenciadas.

Outro procedimento que reforça tal afirmação são as próprias aulas-laboratório, realizadas dentro da estrutura do estágio, que, para Perrenoud (2002), tornam-se procedimentos concretos de formação em prática reflexiva, pois envolvem situações reais presenciadas. Portanto, é em virtude dessas aulas que se aprende a ensinar com a experiência. Uma experiência que necessita ser refletida, pois, conforme Gil (2004), o conhecimento só há de emergir da reflexão sobre os resultados vividos. Além disso, um dos itens que pode orientar as ideias básicas para uma formação que vise à profissionalização e à prática reflexiva dos docentes, segundo Perrenoud (2002), é a realização de uma transposição didática baseada na análise das práticas e de suas transformações. 
Para Hernández (2004), o novo conhecimento que emerge da reflexão sobre a prática poderia vir de três modos integrativos: a) pela utilização de um conhecimento base (que inclua tanto os saberes disciplinares quanto as experiências pessoais); b) pela elaboração de estratégias para seguir aprendendo (como o PFI faz para continuar a aprender?); e c) pela disponibilidade dos professores para a aprendizagem (qual o tempo investido pelo PFI para manter-se aprendendo?).

Conectar esses três modos pode facilitar a aprendizagem dos saberes de ofício, ou seja, dos saberes a ensinar. Em nossa leitura, o componente curricular, na sua concepção, sinaliza a incorporação desses três modos de forma integrativa. Isso acontece, por exemplo, quando o componente possibilita ao PFI, em um primeiro momento, construir sua base de conhecimento no percurso do estágio, por meio de um caminho formativo; num segundo momento, quando regula a necessidade de vivência prática reflexiva por intermédio de um conjunto de horas mínimas na escola; e, num terceiro momento, quando se utiliza de estratégias para favorecer a aprendizagem dos próprios PFI.

\section{Conclusão}

O caminho formativo identificado como base estruturante acena para uma prática pedagógica dos PFI com alta tendência reflexiva, que se baseia em uma intervenção repleta de saberes docentes. Essa descrição fica mais evidente quando realizamos a aproximação entre esse caminho formativo e a TD.

A base estruturante identificada assinala uma TD que vai se materializando por meio de um cenário construído à sua volta. A TD, nessa dimensão, acontece mediada pela atmosfera que a envolve, na qual estariam presentes saberes de referência, saberes a ensinar, saberes para ensinar, não saberes docentes, teorias educacionais, abordagens pedagógicas, conflitos percebidos, reflexões verbalizadas, entre outros elementos.

O caminho formativo ajuda-nos a compreender a configuração estrutural das manipulações por que passam os saberes até se tornarem ensináveis para os PFI. Num primeiro momento, isso acontece pela validação da incorporação/criação de um ambiente clínico/laboratorial para a formação/intervenção, no qual se possa refletir, discutir, observar e verbalizar experiências vividas e teorizadas.

Já em um segundo momento, isso acontece em virtude da descrição desse fluxo de formação com seus planos e seus distintos momentos e esferas. Portanto, podemos perceber, considerando as falas, os escritos e as observações, a relevância de três possíveis elementos (reflexão, observação e discussão no grupo focal) que influenciaram a atuação dos PFI.

Em investigações futuras, aprofundaremos esses elementos, que já oferecem indícios de sua presença na prática pedagógica dos PFI e que, portanto, abrem diálogos com as suas implicações na aplicabilidade da TD. 


\section{Referências bibliográficas}

ALMEIDA, P. C.; BIAJONE, J. Saberes docentes e formação inicial de professores: implicações e desafios para as propostas de formação. Educação e Pesquisa, São Paulo, v. 33, n. 2, p. 281-295, maio/ago. 2007.

BARDIN, L. Análise de conteúdo. 8. ed. Lisboa: Edição 70, 2008.

BEZERRA, Elizabeth Jatobá. Educar para a solidariedade: uma perspectiva para a educação física escolar. 2007. 345 f. Tese (Doutorado) - Programa de Pós-graduação em Educação, Universidade Federal do Rio Grande do Norte, Natal, 2007.

BORGES, C. Saberes docentes: diferentes tipologias e classificações de um campo de pesquisa. Educação \& Sociedade, ano XXII, n. 74, abr. 2001.

BORGES, C. O professor de educação básica e seus saberes docentes. Araraquara: JM, 2004.

CHEVALLARD, Y. La transposición didáctica: del saber sabio al saber enseñado. 3. ed. Buenos Aires: AIQUE, 1998.

FEIMAN-NEMSER, S.; BUCHMANN, M. Describing teacher education: a framework and illustrative findings from a longitudinal study of six students. The Elementary School Journal, v. 89, n. 3, p. 365-377, 1989.

FERREIRA, R. M. N. A prática de ensino enquanto elemento de construção de saberes e competências. In: ENCONTRO DE PESQUISA EM EDUCAÇÃO DA UFPI, 2., 2002, Teresina. Anais...Teresina: UFPI, 2002.

FREIRE, J. B. Educação de corpo inteiro. São Paulo: Scipione, 1989.

FREIRE, J. B; SCAGLIA, A. J. Educação como prática corporal. São Paulo: Scipione, 2009.

GARILIO, J. A. O professor da educação básica e seus saberes profissionais. Educação \& Sociedade, Campinas, v. 27, n. 95, p. 603606, maio/ago., 2006.

GAUTHIER, C. et al. Por uma teoria da Pedagogia: pesquisas contemporâneas sobre o saber docente. 2. ed. Ijui: Unijuí, 2006.

GIL, J. M. S. Inovação e investigação educativa: aproximação a uma relação incerta. In: MOLINA NETO, V.; TRIVIÑOS, A. N. (Org.). 
A pesquisa qualitativa na Educação Física: alternativas metodológicas. 2. ed. Porto Alegre: UFRGS, 2004. p. 29-43.

GOMES-DA-SILVA, P. N. Prática de ensino em educação física: por uma formação do professor-pesquisador. In: HERMIDA, J. F. (Org.). Educação Física: conhecimento e saber escolar. João Pessoa: UFPB, 2009. p.103-128.

HERNANDEZ, F. A formação do professorado e a investigação sobre a aprendizagem dos docentes. In: MOLINA NETO, V.; TRIVIÑOS, A. N. (Org.). A pesquisa qualitativa na Educação Física: alternativas metodológicas. 2. ed. Porto Alegre: UFRGS, 2004. p. 45-60.

ILHA, F. R; KRUG, H. N. Docência no ensino superior: a promoção da autonomia e da reflexão crítica no curso de licenciatura em Educação Física. Revista Digital EFdeportes, Buenos Aires, v. 13, n. 122, jul. 2008. Disponível em: < http://www.efdeportes.com/efd122/reflexaocritica-no-curso-de-licenciatura-em-educacao-fisica.htm $>$. Acesso em: 16 ago. 2009.

LEITE, M. S. Recontextualização e transposição didática: introdução à leitura de Basil Bernstein e Yves Chevallard. Araraquara, SP: Junqueira \& Marin, 2007.

MARANDINO, M. A prática de ensino nas licenciaturas e a pesquisa em ensino de ciências: questões atuais. Caderno Brasileiro de Ensino de Física, Florianópolis, v. 20, n. 2, p.168-193, ago. 2003.

MARCON, D.; GRAÇA, A. B; NASCIMENTO, J. V. Reinterpretação da estrutura teórico-conceitual do conhecimento pedagógico do conteúdo. Revista Brasileira de Educação Física e Esporte, São Paulo, v. 25, n. 2, p. 323-339, abr./jun. 2007.

MARTINY, L. E. A transposição didática na educação física escolar: a prática pedagógica dos professores em formação inicial e a relação com seus saberes docentes. 2012. 173 f. Dissertação (Mestrado em Educação Física) - Universidade Estadual de Pernambuco/ Universidade Federal da Paraíba, Recife/ João Pessoa, 2012.

MATEUS, E. F. et al. A prática do ensino de inglês: desenvolvimento de competências ou legitimação das crenças? Revista Brasileira de Linguística Aplicada, v. 2, n. 1, p. 43-59, 2002.

MINAYO, M. C. S. O desafio do conhecimento: pesquisa qualitativa em saúde. 6. ed. São Paulo: Hucitec; Rio de Janeiro: Abrasco, 1999.

MIRANDA, M. I. Ensino e pesquisa: o estágio como espaço de articulação. In: SILVA, L. C.; MIRANDA, M. I. (Org.). Estágio 
supervisionado e prática de ensino: desafios e possibilidades.

Araraquara, SP: Junqueira\&Marin, 2008. p. 15-36.

MOREIRA, E.C; PEREIRA, R. S. Novos olhares para as práticas de ensino e possíveis contribuições na formação de professores de Educação Física. Revista Digital EFDeportes, Buenos Aires, v. 12, n. 108, maio 2007.

ONOFRE, M. S. Prioridades de formação didática em Educação Física. Boletim da Sociedade Portuguesa de Educação Física, n. 12, p. 75-97, inverno/primavera, 1995.

PERRENOUD, P. A prática reflexiva no ofício de professor:

profissionalização e razão pedagógica. Porto Alegre: Artmed, 2002.

PERRENOUD, P. Práticas pedagógicas, profissão docente e formação: perspectivas sociológicas. Lisboa: D. Quixote, 1993.

SHULMAN, L. S. Those who understand: knowledge growth in teaching. Educational, v. 15, n. 2, p. 4-14, 1986.

SOUZA JÚNIOR, M.; MELO, M. S. T; SANTIAGO, M. E. A análise de conteúdo como forma de tratamento dos dados numa pesquisa qualitativa em Educação Física escolar. Movimento, Porto Alegre, v. 16, n. 3. p. 29-47, jul./set. 2010.

TARDIF, M. Saberes docentes e formação profissional. 9. ed. Petrópolis: Vozes, 2008.

THIOLLENT, M. Metodologia da pesquisa-ação. 13. ed. São Paulo: Cortez, 2004.

Luis Eugênio Martiny, mestre em Educação Física pela Universidade Federal da Paraíba (UFPB), é professor do Instituto Federal de Educação, Ciência e Tecnologia do Rio Grande do Norte (IFRN), Natal, Rio Grande do Norte, Brasil.

luis_martiny@hotmail.com

Pierre Normando Gomes-da-Silva, doutor em Educação pela Universidade Federal do Rio Grande do Norte (UFRN), é professor do Departamento de Educação Física da Universidade Federal da Paraíba (UFPB), João Pessoa, Paraíba, Brasil.

pierrenormandogomesdasilva@gmail.com

Recebido em 3 de junho de 2013.

Aprovado em 26 de dezembro de 2013. 